\title{
Unbinding Process of Amelogenin and Fibrinogen Adsorbed on Different Solid Surfaces Using AFM
}

\author{
__ Unbinding of Adsorbed Amelogenin and Fibrinogen Using AFM
}

\author{
Ludovic Richert ${ }^{1,2,3}$, Abdessamad Boukari ${ }^{2}$, Simon Berner ${ }^{4}$, Michel Dard ${ }^{4}$, Joseph Hemmerlé ${ }^{*}$ \\ ${ }^{1}$ Inserm National de la Santé et de la Recherche Médicale, Strasbourg, France; ${ }^{2}$ Dental School, University of Strasbourg, 1 place de \\ l'hôpital, Strasbourg, France; ${ }^{3}$ Centre National de la Recherche Scientifique, UMR 7213, Institute of Pharmacy, University of Strasbourg, \\ Illkirch, France; ${ }^{4}$ Institut Straumann AG, Peter Merian-Weg 12, Basel, Switzerland. \\ Email: *joseph.hemmerle@medecine.u-strasbg.fr
}

Received March $4^{\text {th }}, 2011$; revised April 10 $0^{\text {th }}$ 2011; accepted May $4^{\text {th }}, 2011$.

\begin{abstract}
The interaction of proteins with solid surfaces is a fundamental phenomenon in the biomaterials field. We investigated, using atomic force microscopy (AFM), the interactions of a recombinant amelogenin with titanium, a biphasic calcium phosphate $(B C P)$ and mica. The unbinding processes were compared to those of an earlier studied protein, namely fibrinogen. Force spectroscopy (AFM) experiments were carried out at $0 \mathrm{~ms}, 10^{2} \mathrm{~ms}, 10^{3} \mathrm{~ms}$ and $10^{4} \mathrm{~ms}$ of contact time. In general, the rupture forces increased as a function of interaction time. The unbinding forces of amelogenin interacting with the BCP surface were always stronger than those of the amelogenin-titanium system. The unbinding forces of fibrinogen interacting with the BCP surface were always much stronger than those of the fibrinogen-titanium system. For the most part, this study provides direct evidence that recombinant amelogenin binds more strongly than fibrinogen on the studied substrates.
\end{abstract}

Keywords: Amelogenin, Titanium, Calcium Phosphate, Force-Mode AFM

\section{Introduction}

The interaction of proteins with solid surfaces is the first step in the integration of an implanted device [1]. Initial interactions between macromolecules and a given substrate influence cell response at the cell-biomaterial interface [2].

Amelogenins are the major extracellular matrix protein in developing dental enamel. They constitute $90 \%$ of the proteins present during enamel formation [3]. Amelogenins are a family of hydrophobic proteins derivable from a single gene by alternative splicing and controlled post secretory processing. The $\mathrm{C}$-terminal region of the protein is composed of a sequence of hydrophilic and charged amino acids [4]. Amelogenin protein interacts, at the extra-cellular level, with calcium and phosphate ions to control the nucleation, growth and organization of the apatite crystals of tooth enamel [1].

Protein adsorption is highly dependent on the individual nature of the protein and the surface involved $[1,5]$. Titanium and its alloys are widely used in orthopedic and oral implants. They have polycrystalline structures with different crystallographic orientations. Physical properties of polycrystalline materials strongly depend on the distribution of the crystallographic orientations of the surface grains [2]. Hydroxyapatite is the predominant inorganic component of human bones and teeth [6]. It has received much attention in materials science and medical fields because of its special surface interaction properties and biocompatibility $[7,8]$. Currently it is widely used in many medical practices such as bone implants [9]. It was found that when hydroxyapatite is exposed in the organism matrix in vivo, its surface is rapidly covered by a proteinous layer [10]. The atomic order of a mineral substrate such as hydroxyapatite can serve as an ordered template to interact with the functional groups of the proteins [2]. For instance, it has been shown that osteocalcin can only interact with calcium ions in specific crystallographic planes in the hydroxyapatite lattice [11].

Techniques that operate at the molecular scale provide investigators with unique approaches to characterize biomolecular mechanisms. Recent advances in the field of scanning probe techniques, particularly in atomic force 
microscopy, have yielded insights into the protein selfassembly and the mechanisms of protein unfolding. Monitoring the tip-sample interactions with an atomic force microscope is a powerful tool for in situ measurements and real-time assessments of biomolecular phenomena [12].

Despite extensive studies, basic questions on the behavior of a protein in its adsorbed state are still difficult to answer [1]. We used atomic force spectroscopy (AFM) to produce new data about the molecular mechanisms governing the interactions between amelogenin and different substrates. The aim of this investigation was to analyze the adsorption process of a pure recombinant amelogenin and how the physico-chemical surface properties of common implant surfaces (titanium and biphasic calcium phosphate) can affect this process. As fibrinogen plays a crucial role in protein adsorption on artificial surfaces [13] and its adhesion mechanisms are available onto different substrates [14,15], we used fibrinogen for comparison with amelogenin. Since freshly cleaved mica offers a very flat and monocrystalline surface, we used it as a comparative adsorbent substrate. The ultimate goals of these assessments were to measure, understand and predict interfacial aspects of the protein-surface phenomena on the molecular level.

\section{Materials and Methods}

\subsection{Titanium Substrate}

Commercially pure titanium discs were provided by Institut Straumann AG (Institut Straumann AG, Peter Merian-Weg 12, Basel, Switzerland). The discs were prepared from $1 \mathrm{~mm}$ thick sheets of titanium grade 2 . Metal disks were polished mechanically to a mirror finish.

\subsection{Biphasic Calcium Phosphate (BCP)}

Biphasic calcium phosphate (BCP) was prepared by mixing calcium hydroxide $\left(\mathrm{Ca}(\mathrm{OH})_{2}\right)$ and phosphoric acid $\left(\mathrm{H}_{3} \mathrm{PO}_{4}\right)$ to ensure homogenous phase distribution. The HA/TCP ratio $(60: 40)$ was reached by optimizing the concentrations of the reagents and the synthesis conditions ( $\mathrm{pH}$ and temperature). Crystallographic data of the HA/TCP material were documented by X-ray diffraction analysis (Rigaku CN 2005, Rigaku Corporation, Tokyo, Japan). Biphasic calcium phosphate substrates were chemically characterized by energy dispersive $\mathrm{X}$-ray analysis and disclosed a $\mathrm{Ca} / \mathrm{P}$ atomic ratio of 1.48 (data not shown).

\subsection{Mica}

High quality muscovite mica sheets were purchased (Euromedex, Souffelweyersheim, France). Freshly cleaved mica surfaces were used.

\subsection{Surface Treatment}

All substrates were cleaned by sonication, at a frequency of $40 \mathrm{kHz}$ for $10 \mathrm{~min}$, in ethanol and were subsequently treated by ultraviolet-ozone irradiation (BioForce UV. TC. EU 003, Nanosciences, Inc. Iowa, USA) for $20 \mathrm{~min}$.

\subsection{Atomic Force Microscopy}

The experiments were performed with a NanoScope IV (Veeco Metrology group, Santa Barbara, CA, USA) instrument equipped with a PicoForce device. All measurements were realized in liquid environment $(0.15 \mathrm{M}$ $\mathrm{NaCl}, 10 \mathrm{mM}$ tris, $\mathrm{pH}$ 7.4) at room temperature. A ramp size of $500 \mathrm{~nm}$ was used for the sample movement. Approach and retraction rates were equal to $1 \mu \mathrm{m} \cdot \mathrm{s}^{-1}$. Contact times varied between 0 and $10^{4} \mathrm{~ms}$. About 50 approaching-retracting cycles were carried out per experimental condition, at three different places with the same protein (amelogenin or fibrinogen) coated cantilever. The average values of all forces, recorded for each experiment, were used for further interpretations. All results are expressed as mean \pm standard error.

\subsection{Cantilevers}

MSCT cantilevers (Veeco Metrology group, Santa Barbara, CA, USA) were used either with tip C $\left(10 \mathrm{pN} \cdot \mathrm{nm}^{-1}\right)$ or with tip $\mathrm{D}\left(30 \mathrm{pN} \cdot \mathrm{nm}^{-1}\right)$. The spring constants were confirmed by a thermal fluctuations method [16]. An incubation time of $30 \mathrm{~min}$ at room temperature was applied for protein adsorption at the cantilever tips. Curves acquired with protein coated tips were compared to non-coated tips to make sure that the tips were properly coated. Force curves did not show noticeable differences after coated cantilevers where left up to $60 \mathrm{~min}$ in buffer solution, thus indicating the stability of the adsorbed proteins.

\subsection{Proteins}

Recombinant human amelogenin was prepared as follows:

A gene encoding the X-chromosomal human 175 amino acid amelogenin (NCBI accession number AAA51717, excluding the 16 amino acid $\mathrm{N}$-terminal signal peptide) was synthesized by PCR. Nine oligonucleotides were used to build the gene, which was codon optimized for $E$. coli. The assembled amelogenin gene was amplified, by using flanking primers and the assembly mixture as template, and subsequently cloned into a cloning vector. The gene was sequenced and point mutations were corrected. The gene was finally inserted in the expression vector pET11a (EMD4Biosciences, Novagen, Darmstadt, Germany). All cultivation was carried out in shake flasks 
using the $E$. coli expression strain BL21. The purification was conducted by a multistep centrifugation process and reverse phase high performance liquid chromatography [17]. This recombinant human amelogenin is nonglycosylated.

Human fibrinogen (Sigma \# F-4883) was purchased from Sigma. The purity of the sample was checked by $\mathrm{AgNO}_{3}$-stained SDS/PAGE. It was used without further purification.

\subsection{Protein Preparation}

The protein solutions were prepared by dissolving $10 \mathrm{mg}$ of recombinant human amelogenin or human fibrinogen in $1 \cdot \mathrm{mL}$ of MilliQ water $(\rho=18.2 \mathrm{M} \Omega \cdot \mathrm{cm})$. Working solutions corresponded to $1 \mathrm{mg} \cdot \mathrm{mL}^{-1}$ dilutions $(0.15 \mathrm{M}$ $\mathrm{NaCl}, 10 \mathrm{mM}$ tris, $\mathrm{pH}$ 7.4).

\subsection{Statistical Analysis}

Data analysis was performed using the Kruskal-Wallis one way analysis of variance on ranks (ANOVA on ranks) by means of the computer software package SigmaStat ${ }^{\circledR}$ (SPSS Inc., Chicago, IL, USA). All pairwise multiple comparisons have been performed with the Dunn's method. The existence of significant differences was determined with a $P$-value $<0.05$ ( $p$ or probability to have really the same median).

\section{Results}

The surface topography of the titanium, biphasic calcium phosphate and mica substrates were analyzed by atomic force microscopy. Table 1 sums up the roughness measurements for the three surfaces at given scanning sizes. For instance, for $5 \times 5 \mu \mathrm{m}^{2}$ scanning dimensions, the measured height $(Z)$ values were $6 \pm 1 \mathrm{~nm}, 76 \pm 7 \mathrm{~nm}$ and less than $0.2 \mathrm{~nm}$ for titanium, BCP and mica surfaces respectively.

Reproducible force-distance curves were obtained throughout the different experiments. Figure 1 shows typical force vs. distance curves obtained for amelogenin protein interacting with each substrate (respectively titanium, biphasic calcium phosphate and mica for a contact time of $10^{4} \mathrm{~ms}$. The effects of interaction time were assessed at $0 \mathrm{~ms}, 10^{2} \mathrm{~ms}, 10^{3} \mathrm{~ms}$ and $10^{4} \mathrm{~ms}$. Consecutive measurements were performed at different locations of the substrate to confirm that we actually were measuring protein-surface interactions. As the different approachretraction sequences showed equivalent force curves, that were different from others obtained with a bare tip, we definitely could attribute the collected data to proteinsurface interactions. Force measurements were carried out by loading at a rate of $1 \mu \mathrm{m} \cdot \mathrm{s}^{-1}$ followed by unloading at the same rate.

When amelogenin coated cantilevers were brought
Table 1. Roughness measurements (Root mean square or RMS), determined by AFM, of respectively titanium, BCP and mica surfaces for different scanning sizes.

\begin{tabular}{cccc}
\hline Scan size $\left(\boldsymbol{\mu m}^{2}\right)$ & Titanium & BCP & Mica \\
\hline $50 \times 50$ & $14 \pm 1.5 \mathrm{~nm}$ & $424 \pm 30 \mathrm{~nm}$ & $<0.5 \mathrm{~nm}$ \\
$10 \times 10$ & $6 \pm 1.5 \mathrm{~nm}$ & $176 \pm 38 \mathrm{~nm}$ & $<0.5 \mathrm{~nm}$ \\
$5 \times 5$ & $6 \pm 1 \mathrm{~nm}$ & $76 \pm 7 \mathrm{~nm}$ & $<0.2 \mathrm{~nm}$ \\
\hline
\end{tabular}

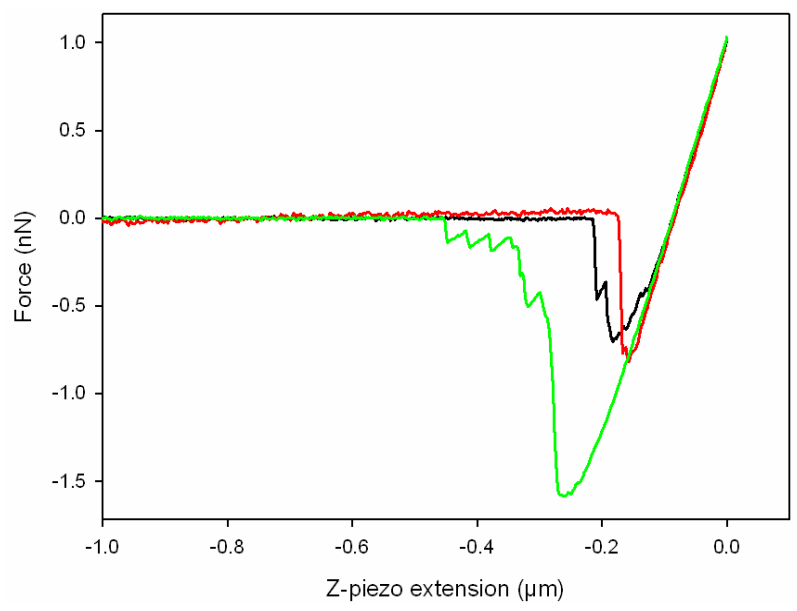

Figure 1. Typical force vs. distance curves obtained for amelogenin interacting with titanium (black curve), biphasic calcium phosphate (red curve) and mica (green curve) for a contact time of $10000 \mathrm{~ms}$.

into contact with the three different substrates, it appeared that the dissociation force increased as a function of contact time for the three investigated systems (Figure 2). As depicted on the bar chart of Figure 2, in general, the rupture forces were the strongest for the amelogeninmica pair. On the other hand, one can note that the unbinding forces of amelogenin interacting with the $\mathrm{BCP}$ surface were always stronger than those of the amelogenin-titanium system (Figure 2). For example, at a contact time of $10^{3} \mathrm{~ms}$ the average force needed to break off the contact between amelogenin and the BCP surface was equal to $1.38 \pm 0.04 \mathrm{nN}$, whereas an average rupture force of $0.58 \pm 0.03 \mathrm{nN}$ was calculated for the amelogenin-titanium interaction.

When fibrinogen coated cantilevers were brought into contact with the three different substrates, it appeared that the dissociation force increased as a function of contact time for the three investigated systems (Figure 3). The results depicted on the bar chart of Figure 3 clearly show that fibrinogen binds strongly to the $\mathrm{BCP}$ substrate; even at short contact times $(0.57 \pm 0.04$ and $0.53 \pm 0.03$ $\mathrm{nN}$ ) for 0 and $100 \mathrm{~ms}$, respectively. Moreover, one can note that the unbinding forces of fibrinogen interacting 


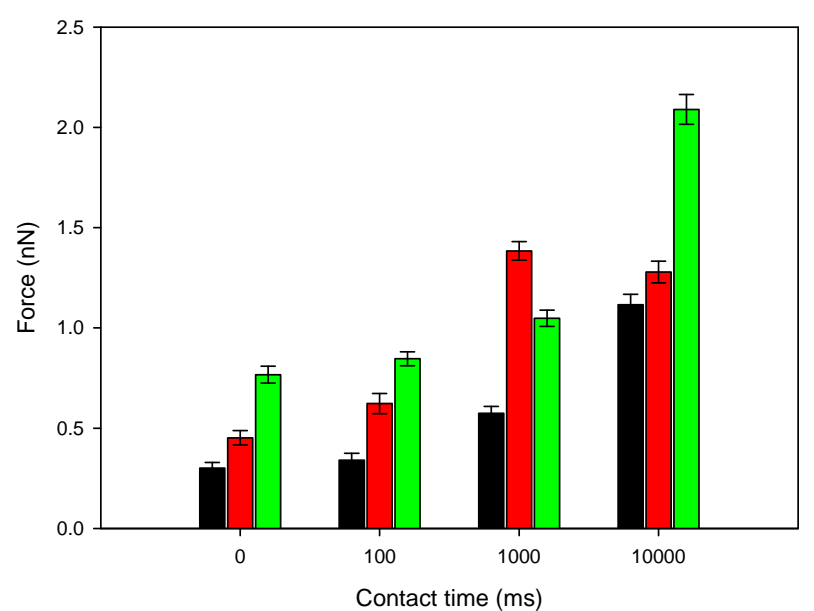

Figure 2. Mean adhesion forces after interactions of amelogenin with titanium (black bars), BCP (red bars) and mica (green bars) surfaces for respectively $0,100,1000$ and 10000 ms contact times. Error bars represent the standard error on the mean.

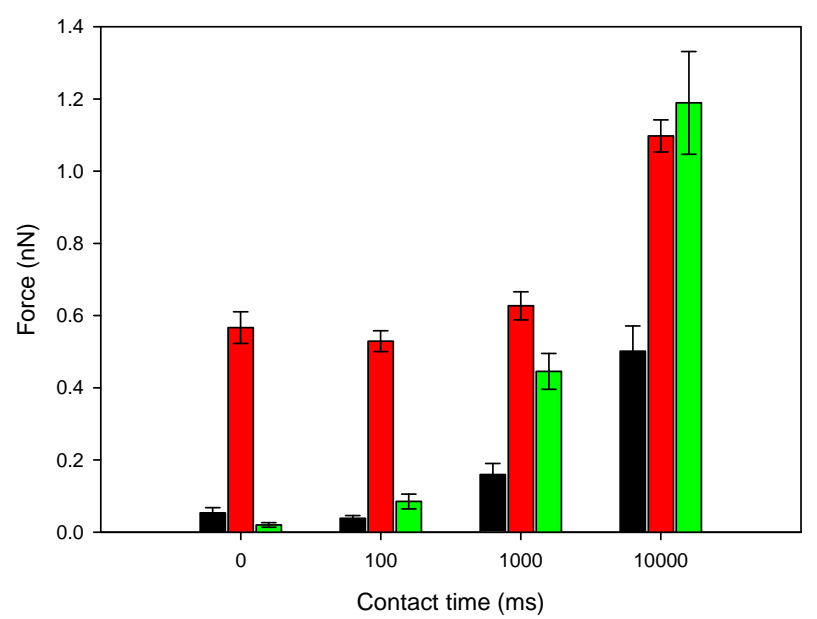

Figure 3. Mean adhesion forces after interactions of fibrinogen with titanium (black bars), BCP (red bars) and mica (green bars) surfaces for respectively $0,100,1000$ and 10000 ms contact times. Error bars represent the standard error on the mean.

with the BCP surface were always much stronger than those of the fibrinogen-titanium system (Figure 3). For example, at a contact time of $10^{3} \mathrm{~ms}$ the average force needed to break off the contact between fibrinogen and the $\mathrm{BCP}$ surface was equal to $0.63 \pm 0.04 \mathrm{nN}$, whereas an average rupture force of $0.16 \pm 0.03 \mathrm{nN}$ was calculated for the fibrinogen-titanium interaction.

A summary of the adhesion force of all investigated protein-substrate pairs is plotted in Figure 4. As follows from Figure 4, the recombinant amelogenin protein binds stronger, compared to fibrinogen protein, and this independently of the surface (titanium, BCP or mica) and

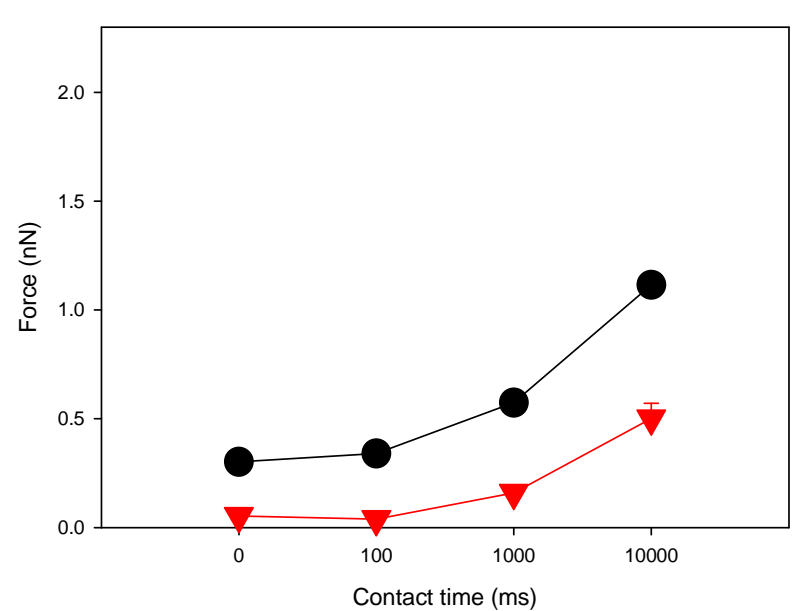

(a)

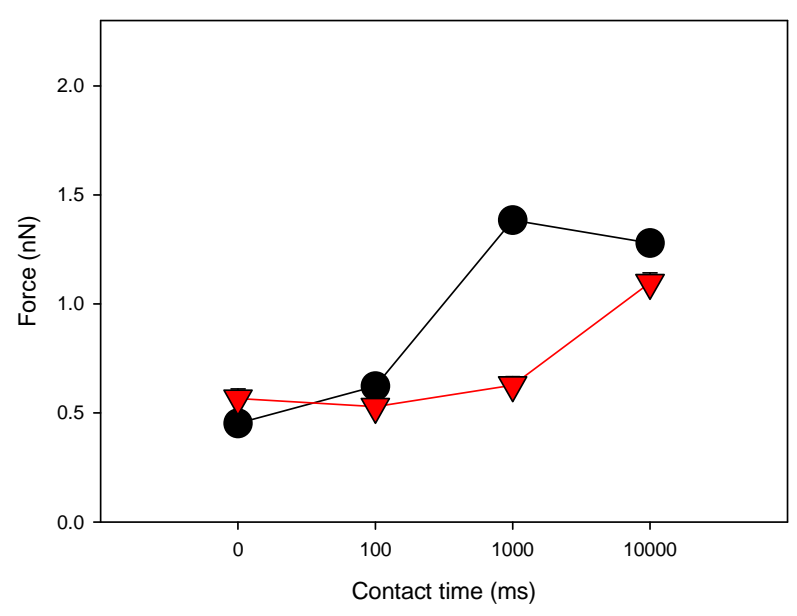

(b)

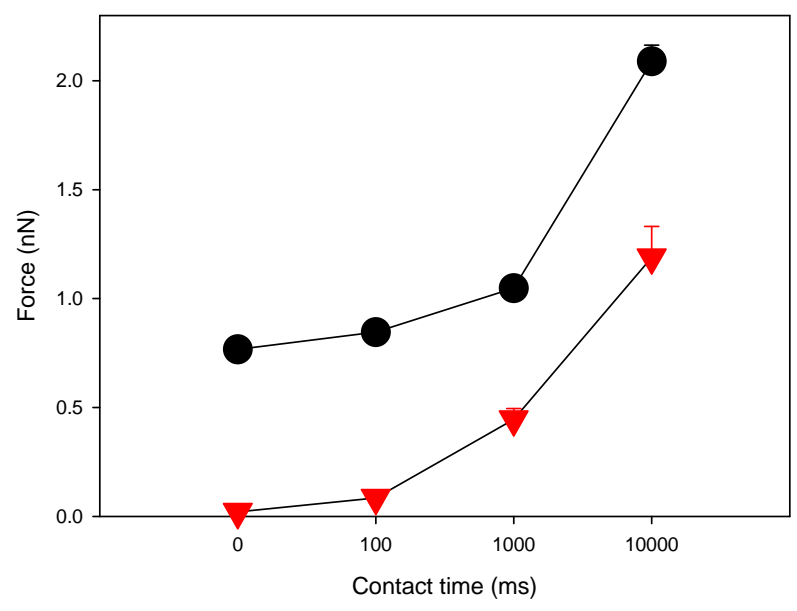

(c)

Figure 4. Effect of contact times (respectively $0 \mathrm{~ms}, 10 \mathrm{~ms}$, $100 \mathrm{~ms}$ and $1000 \mathrm{~ms}$ ) after interactions of amelogenin $(O)$ and fibrinogen ( $\nabla$ ) with (a) titanium, (b) BCP and (c) mica surfaces. Error bars represent the standard error on the mean. 
the considered contact times (except on BCP at $0 \mathrm{~ms}$ ).

\section{Discussion}

The purpose of the present assessments was to analyze how the physico-chemical surface properties of titanium and calcium phosphate can affect the adsorption process of recombinant human amelogenin. Fibrinogen was used as a reference protein for comparison with amelogenin. Mica was used as a reference surface since it exposes always the same crystallographic plane of the crystal lattice to the proteins.

AFM can measure very small (about $10 \mathrm{pN}$ ) forces between the tip and a surface. Force spectroscopy has provided new insights into protein-surface interactions [14]. By fastening a ligand of interest to the AFM tip and bringing the modified tip into contact with a surface, one can, in principle, directly measure the attractive and repulsive intermolecular forces as a function of the tipsample separation distance on the molecular level [12]. In a conventional force spectroscopy experiment, the deflection of a force microscope cantilever with a known spring constant is monitored while a surface of interest is moved towards the AFM tip until contact is made and then retracted. Once the cantilever's restoring force exceeds the attractive force between the protein- coated tip and the surface, a pull-off event does occur. The vertical jump during pull-off can be used to calculate the interaction force on the basis of Hooke's law [12].

The advantage of applying AFM for adhesion force measurements is the possibility of deriving quantitative data directly for the interaction phenomena of submicroscopic contact areas in aqueous solutions. Thus contact experiments can be described on an atomistic level [18]. However, forces measured by AFM cannot be trivially related to binding affinities [12]. As shown earlier, the unbinding force, measured when the molecule separates from the substrate, depends to a large extend on the dissociation rate at which the pulling force is applied $[19,20]$. Present measurements were carried out by loading at a rate of $1 \mu \mathrm{m} \cdot \mathrm{s}^{-1}$ followed by unloading at the same rate.

Amelogenin proteins are hydrophobic in nature, with most of the charged amino acids located in the $\mathrm{N}$ - and $\mathrm{C}$-terminal segments [3]. The C-terminal amino acids of amelogenin are hydrophilic [21]. The loss of the charged $\mathrm{COO}^{-}$terminal of amelogenin results in a reduction of the affinity to hydroxyapatite [22]. Amelogenin molecules spontaneously self-assemble into spherical structures called nanospheres [23]. Available data suggest that the cooperative self-assembly of amelogenins is $\mathrm{pH}$-dependent [24]. The $\mathrm{pH}$ during the secretory stage of amelogenesis is tightly regulated between $\mathrm{pH} 7.2$ and 7.4. A major challenge in working with enamel matrix pro- teins in vitro is that their solubility under the latter physiological conditions is very low [25]. Nevertheless, present experiments were performed in liquid environ- ment at $\mathrm{pH} 7.4$ to approach physiological conditions.

Our investigations give new insight into the underlying behaviors of amelogenin and fibrinogen adsorbed onto substrates of interest in the biomaterials field. The force curves we obtained are characteristic for protein-surface unbinding processes. In all cases studied here, it is evident that the unbinding forces of the adsorbed proteins increase steadily as a function of contact time. That is consistent with previously published results $[14,15]$. Present analyses demonstrate that the unbinding forces of amelogenin interacting with the BCP surface are always stronger than those of the same protein interacting with the titanium substrate. It appears also that the rupture forces of fibrinogen interacting with the BCP surface are always much stronger than those of the same protein interacting with the titanium surface. Interestingly our results clearly indicate that the recombinant human amelogenin always binds more strongly than fibrinogen independently of the surface (titanium, BCP or mica) and the contact time $\left(0,10^{2}, 10^{3}\right.$ and $\left.10^{4} \mathrm{~ms}\right)$. These findings emphasize the implication of the physico-chemical properties of the surface in the unbinding process of adsorbed proteins.

\section{Acknowledgements}

We acknowledge support from the Région Alsace for financial contribution to the AFM equipment. L.R. is indebted to the Faculte de Chirurgie Dentaire of Strasbourg for financial support. M.D. greatly appreciated the contributions of J. Svensson and L. Bülow (University of Lund, Sweden).

\section{REFERENCES}

[1] J. J. Gray, "The Interaction of Proteins with Solid Surfaces," Current Opinion in Structural Biology, Vol. 14, No. 1, 2004, pp. 110-115. doi:10.1016/j.sbi.2003.12.001

[2] S. Faghihi, F. Azari, H. Li, M. R. Bateni, J. A. Szpunar, H. Vali and M. Tabrizian, "The Significance of Crystallographic Texture of Titanium Alloy Substrates on Pre- osteoblast Responses," Biomaterials, Vol. 27, No. 19, 2006, pp. 3532-3539.

[3] A. G. Fincham, J. Moradian-Oldack and J. P. Simmer, "The Structural Biology of the Developing Dental Enamel Matrix," Journal of Structural Biology, Vol. 126, No. 3, 1999, pp. 270-299. doi:10.1006/jsbi.1999.4130

[4] J. Moradian-Oldak, "Amelogenins: Assembly, Processing and Control of Crystal Morphology," Matrix Boilogy, Vol. 20, No. 5-6, 2001, pp. 293-305.

[5] L. Richert, F. Variola, F. Rosei, J. Wuest and A. Nanci, "Adsorption of Proteins on Nanoporous Ti Surfaces," Sur- 
face Science, Vol. 604, No. 17-18, 2010, pp. 1445-1451. doi:10.1016/j.susc.2010.05.007

[6] H. Zhou, T. Wu, X. Dong, Q. Wang and J. Shen, “Adsorption Mechanism of BMP-7 on Hydroxyapatite (001) Surfaces," Biochemical and Biophysical Research Communications, Vol. 361, No. 1, 2007, pp. 91-96. doi:10.1016/j.bbrc.2007.06.169

[7] R. Goobes, G. Goobes, C. T. Campbell and P. S. Stayton, "Thermodynamics of Statherin Adsorption onto Hydroxyapatite," Biochemistry, Vol. 45, No. 17, 2006, pp. 5576-5586. doi:10.1021/bi052321z

[8] J. Hemmerlé, F. J. G. Cuisinier, P. Schultz and J.-C. Voegel, "HRTEM Study of Biological Crystal Growth Mechanisms in the Vicinity of Implanted Synthetic Hydroxyapatite Crystals," Journal of Dental Research, Vol. 76, No. 2, 1997, pp. 682-687. doi:10.1177/00220345970760020901

[9] J. Hemmerlé, A. Önçag and S. Ertürk, "Ultrastructural Features of the Bone Response to a Plasma-Sprayed Hydroxyapatite Coating in Sheep," Journal of Biomedical Materials Research, Vol. 36, No. 3, 1997, pp. 418-425. doi:10.1002/(SICI)1097-4636(19970905)36:3<418::AIDJBM17>3.0.CO;2-9

[10] K. Kandori, N. Horigami, H. Kobayashi, A. Yasukawa and T. Ishikawa, "Adsorption of Lysozyme onto Various Synthetic Hydroxyapatites," Journal of Colloid and Interface Science, Vol. 191, No. 2, 1997, pp. 498-502. doi:10.1006/jicis.1997.4943

[11] Q. Q. Hoang, F. Sicheri, A. J. Howard and D. S. Yang, "Bone Recognition Mechanism of Porcine Osteocalcin from Crystal Structure," Nature, Vol. 425, 2003, pp. 977980. doi:10.1038/nature02079

[12] C. M. Yip, "Atomic Force Microscopy of Macromolecular Interactions," Current Opinion in Structural Biology, Vol. 11, No. 5, 2001, pp. 567-572. doi:10.1016/S0959-440X(00)00247-5

[13] S. M. Slack and T. A. Horbett, "Changes in the Strength of Fibrinogen Attachment to Solid Surfaces: An Explanation of the Influence of Surface Chemistry on the Vroman Effect," Journal of Colloid and Interface Science, Vol. 133, No. 1, 1989, pp. 148-165. doi:10.1016/0021-9797(89)90288-9

[14] J. Hemmerlé, S. M. Altmann, M. Maaloum, J. K. H. Hörber, L. Heinrich, J.-C. Voegel and P. Schaaf, "Direct Observation of The Anchoring Process During the Adsorption of Fibrinogen on a Solid Surface by ForceSpectroscopy Mode Atomic Force Microscopy," Proceedings of the National Academy of Sciences of the USA, Vol. 96, No. 12, 1999, pp. 6705-6710. doi:10.1073/pnas.96.12.6705

[15] A. Boukari, G. Francius and J. Hemmerlé, “AFM Force Spectroscopy of the Fibrinogen Adsorption Process onto Dental Implants," Journal of Biomedical Materials Research A, Vol. 78, No. 3, 2006, pp. 466-472. doi:10.1002/jbm.a.30778
[16] T. Thundat, R. J. Warmack, G. Y. Chen and D. P. Allison, "Thermal and Ambient-Induced Deflections of Scanning Force Microscope Cantilevers," Applied Physics Letters, Vol. 64, No. 21, 1994, pp. 2894-2896. doi:10.1063/1.111407

[17] J. Svensson. C. Andersson, J. E. Reseland, P. Lyngsta-daas and L. Bülow, "Histidine Tag Fusion Increases Expression Levels of Active Recombinant Amelogenin in Escherichia Coli," Protein Expression and Purification, Vol. 48, No. 1, 2006, pp. 134-141. doi:10.1016/j.pep.2006.01.005

[18] G. Jänchen, M. Mertig and W. Pompe, "Adhesion Energy of Thin Collagen Coatings and Titanium," Surface and Interface Analysis, Vol. 27, No. 5-6, 1999, pp. 444-449. doi:10.1002/(SICI)1096-9918(199905/06)27:5/6<444::AI D-SIA531>3.0.CO;2-3

[19] C. Gergely, J.-C. Voegel, P. Schaaf, B. Senger, M. Maaloum, J. K. H. Hörber and J. Hemmerlé, "Unbinding Process of Adsorbed Proteins Under External Stress Studied by Atomic Force Microscopy Spectroscopy," Proceedings of the National Academy of Sciences of the USA, Vol. 97, No. 20, 2000, pp. 10802-10807. doi: 10.1073/pnas.180293097

[20] J. Hemmerlé, C. Picart, C. Gergely, P. Schaaf, J.-F. Stoltz, J.-C. Voegel and B. Senger, "Modeling of The Detachment of a Molecule from a Surface: Illustration of the "Bell- Evans Effect," Biorheology, Vol. 40, No. 1-3, 2003, pp. 149-160.

[21] A. G. Fincham, J. Moradian-Oldack, T. G. Diekwish, D. M. Layaruu, J. T. Wright and P. Bringas, "Evidence for Amelogenin "Nanospheres" as Functional Components of Secretory-Stage Enamel Matrix," Journal of Structural Biology, Vol. 115, No. 1, 1995, pp. 50-59. doi:10.1006/jsbi.1995.1029

[22] J. Moradian-Oldak, N. Bouropoulos, L. Wang and N. Gharakhanian, "Analysis of Self-Assembly and Apatite Binding Properties of Amelogenin Proteins Lacking the Hydrophilic C-Terminal," Matrix Biology, Vol. 21, No. 2, 2002, pp. 197-205. doi:10.1016/S0945-053X(01)00190-1

[23] C. Du, G. Falini, S. Fermani, C. Abbott and J. MoradianOldak, "Supramolecular Assembly of Amelogenin Nanospheres into Birefringent Microribbons," Science, Vol. 307, No. 5714, 2005, pp. 1450-1454. doi:10.1126/science. 1105675

[24] X. He, W. Li, S. Habelitz, "The Cooperative Self-Assembly of 25 and $23 \mathrm{kDa}$ Amelogenins," Journal of Structural Biology, Vol. 164, No. 3, 2008, pp. 314-321. doi:10.1016/i.jsb.2008.09.005

[25] F. B. Wiedemann-Bidlack, E. Beniash, Y. Yamakoshi, J. P. Simmer, H. C. Margolis, "pH Triggered Self-Assembly of Native and Recombinant Amelogenins under physiological $\mathrm{pH}$ and Temperature in Vitro," Journal of Structural Biology, Vol. 160, No. 1, 2007, pp. 57-69. doi:10.1016/j.jsb.2007.06.007 